\title{
PERCEPÇÃO DE GESTORES DE HOSPEDAGENS SOBRE PLATAFORMAS DE ALUGUEL ON-LINE POR TEMPORADA
}

\author{
LODGING FACILITY MANAGERS'S PERCEPTIONS OF ONLINE HOME-RENTAL PLATFORMS
}

\section{LA PERCEPCIÓN DE LOS GESTORES DE HOSPEDAJES SOBRE LAS PLATAFORMAS DE ALQUILER ON LINE PARA TEMPORADA}

\section{Karolina Matias Ferreira} Analista Técnica SEBRAE/RJ. Mestre em Sistema de Gestão - Universidade Federal Fluminense (UFF). karolinamatias@gmail.com

Rodrigo Amado dos Santos Docente - Universidade Federal Rural do Rio de Janeiro (UFRRJ), Curso de Bacharelado em Hotelaria. Doutorando em Sistemas de Gestão Sustentáveis - Universidade Federal Fluminense (UFF). profrodrigoamado@gmail.com

Mirian Picinini Méxas Docente - Programa de Pós-Graduação em Sistemas de Gestão Sustentáveis da Universidade Federal Fluminense. Doutora em Engenharia Civil - Universidade Federal Fluminense (UFF). mirian_mexas@vm.uff.br

Marcelo Jasmim Meiriño Docente - Programa de Pós-Graduação em Sistemas de Gestão Sustentáveis da Universidade Federal Fluminense. Doutor em Engenharia Civil - Universidade Federal Fluminense (UFF). marcelo@latec.uff.br

Data de Submissão: 25/01/2017 Data de Aceitação: 05/07/2017

RESUMO: As plataformas on-line de aluguel por temporada vêm ganhando destaque nos últimos anos por representarem uma inovação na prestação do serviço turístico, bem como por afetarem negativamente os resultados dos meios de hospedagem tradicionais. Dito isso, o presente artigo teve por objetivo investigar a percepção de gestores de meios de hospedagem em cinco municípios do Estado do Rio de Janeiro sobre economia compartilhada, consumo colaborativo e plataformas on-line de aluguel por temporada. De caráter exploratório, a pesquisa qualitativa foi realizada por meio de questionários semiestruturados distribuídos pela SurveyMonkey. Seus resultados indicaram uma necessidade de adaptação por parte dessas empresas a esse novo cenário: serviços de hospedagem distribuídos por plataformas on-line a preços inferiores ao do mercado. Pondera-se, portanto, a necessidade de esses gestores estabelecerem estratégias de segmentação ou de diferenciação mercadológica que lhes agreguem um valor superior aos seus empreendimentos de modo que sejam minimizados os efeitos causados por esse novo nicho de mercado.

PALAVRAS-CHAVE: meios de hospedagem, plataformas on-line, economia compartilhada, consumo colaborativo.

ABSTRACT: Online home-rental platforms have increased rapidly, gaining a prominent position in recent years, because they represent an innovation in the provision of tourism services, and have had a negative effect on the results of traditional lodging businesses. In view of this scenario, the aim of this article was to investigate the perceptions of lodging facility managers on shared economy, collaborative consumption, and online home-rental platforms in five different cities in the State of Rio de Janeiro. As this was an exploratory study, a qualitative survey was conducted through semi-structured 
questionnaires, which were distributed via SurveyMonkey. The results indicate that businesses need to adapt to this new scenario: lodging services distributed across online platforms, at prices below those offered by the traditional market. It is noted that there is a need for these managers to create strategies of segmentation or marketing differentiation that would provide added value to their organizations and minimize the effects of this new market niche.

KEYWORDS: hotel businesses, online renting platforms, sharing economy, collaborative consumption.

RESUMEN: Las plataformas on line de alquiler de viviendas entre particulares han ganado importancia en los últimos años debido a que representan una innovación en la prestación del servicio turístico, así como por afectar negativamente los resultados de los medios de alojamiento tradicionales. Dicho esto, el presente trabajo tuvo por objetivo investigar la percepción de los gestores de medios de hospedaje en cinco municipios del Estado de Río de Janeiro sobre la economía compartida, consumo colaborativo y plataformas on line de alquileres vacacionales. De carácter exploratorio, la investigación cualitativa se realizó a través de cuestionarios semiestructurados distribuidos por la SurveyMonkey. Sus resultados indicaron una necesidad de adaptación, por parte de estas empresas, a ese nuevo escenario: servicios de alojamiento distribuidos a través de las plataformas on line, a precios inferiores a los de mercado. Se considera, por lo tanto, la necesidad de que estos gestores establezcan estrategias de segmentación o diferenciación mercadológica que les proporcionen un valor superior a sus emprendimientos, haciendo que este nuevo nicho de mercado no se convierta en un competidor directo de sus organizaciones.

PALABRAS CLAVE: Medios de hospedaje; Plataformas on line; Economía compartida; Consumo colaborativo.

INTRODUÇÃO

sociedade contemporânea presencia práticas econômicas que vão
além das propostas por seu modelo capitalista vigente (Ceroy, 2015).
Como exemplo disso, observa-se, a partir da década de 1990, o surgimento paulatino de um novo posicionamento mercadológico denominado "Economia Compartilhada" (EC) (Shirky, 2008), cujo objetivo seria a proposição de modelos de negociação pautados na troca e/ou no compartilhamento de produtos e/ou bens entre indivíduos (Schor, 2014).

Desse modo, a EC é constituída por práticas comerciais que não se pautam pelas aquisições materiais ou pela necessidade de acúmulo de capital (Botsman \& Borges, 2011). A prerrogativa base deste sistema econômico se sustenta pela acessibilidade, cujos consumidores estariam mais interessados na experiência de usufruto temporária das características, especificidades e particularidades de certas mercadorias, optando por não adquiri-las (Bardhi \& Eckhardt, 2012).

Esse novo sistema econômico fez com que o compartilhamento de bens individuais ociosos se popularizasse nos últimos anos (Choi, Cho, Lee, Hong \& Woo, 2014). Somada essa contextualização à emergência de plataformas 
tecnológicas peer-to-peer (P2P) (Fremstad, 2014), novos marketplaces são constituídos, promovendo mudanças significativas nos padrões de consumo, destacando-se, por exemplo, a questão da simplicidade, da procedência e da transparência como preceitos fundamentais ao processo de gestão e de operacionalização de produtos (Botsman \& Borges, 2011).

Com relação à cadeia produtiva do turismo, Cheng (2016a) enfatiza que o crescimento da EC vem chamando atenção das cadeias hoteleiras, dos gestores públicos e dos acadêmicos, uma vez que: (1) pela perspectiva do empreendedor, nota-se uma interferência decisiva em seus resultados e produtividades organizacionais; (2) pela perspectiva do visitante, amplia o leque de produtos e serviços a serem usufruídos, facilitando encontros autênticos entre autóctones e turistas; (3) pela perspectiva da comunidade, contribui para o aumento do número de empregos e renda local.

No que tange à sua aplicação no setor turístico, a EC pode se manifestar por meio das plataformas on-line de aluguel por temporada, as quais vêm ganhando força através das redes sociais. Basicamente, nessas plataformas digitais, potenciais anfitriões inscrevem seus imóveis, definem o valor das diárias e anunciam aos hóspedes (Zervas, Proserpio, \& Byers, 2015). Como exemplo notório dessa prática, tem-se o Airbnb - http://www.airbnb.com.br - plataforma avaliada em US\$ 18 milhões de dólares (Schor, 2014), que oferece uma gama de opções de hospedagem - mais de 2 milhões de acomodações - já usufruída por 60 milhões de pessoas em mais de 34 mil cidades espalhadas em 191 países (Airbnb, 2016).

A proposta dessas plataformas reside na conexão direta entre viajantes e proprietários de imóveis, provocada graças: (1) ao advento e à difusão e à maximização de recursos tecnológicos e comunicacionais que permitiram uma revolução acerca dos valores, dos posicionamentos e das estratégias das organizações contemporâneas (Turner \& Muñoz, 2001; Cheng, 2016b); (2) a sagacidade de indivíduos que viram, após a crise econômica de 2008, a possibilidade da prática turística como direito lúdico de quaisquer cidadãos e/ ou modo de manter a renda familiar, assegurar seus índices de crescimento por meio de uma nova proposta de acomodação (Teixeira, 2016). 
O que se percebe a partir deste cenário é que essas inovações mudaram, significativamente, a lógica da competição do mercado turístico, forçando seus gestores - em especial ao universo de hospedagem - a adotarem estratégias diferenciadas para continuarem competindo em seus mercados (Christensen, 2001). Justamente por isso, considera-se fundamental compreender os efeitos e os impactos oriundos da EC e de seus instrumentos, expressos pelas plataformas on-line de aluguel por temporada.

Por esta perspectiva, o trabalho chama atenção à necessidade dos gestores hoteleiros contemporâneos compreenderem as possíveis ameaças e/ou oportunidades que a EC pode acarretar às suas operacionalizações e aos resultados organizacionais (Matzler, Veider e Kathan, 2015). Assim, evidenciase aqui uma problemática cujo setor hoteleiro contemporâneo encontra-se deveras vulnerável. E, em longo prazo, os efeitos da EC exigirão que tais empresas ofereçam serviços ainda mais consistentes, confiáveis e seguros para que seja possível lidar com os efeitos que a priorização do compartilhamento dos bens exerce sobre uma possível propriedade material e/ou imaterial (Boesler, 2013; Ceroy, 2015; Cusumano, 2015).

Desta maneira, é imperativo o vislumbre de novas estratégias que sejam capazes de se adaptar a esta nova tendência, que redefine os comportamentos de consumo estabelecidos entre organizações e sociedade (Quinson, 2015). Nesse sentido, os autores buscaram focar suas análises em empreendimentos hoteleiros que já se defrontam com as influências da EC em seus resultados organizacionais. Para tanto, estabeleceu-se um enfoque em cinco municípios do Estado do Rio de Janeiro, sendo esses: Angra dos Reis, Armação dos Búzios, Cabo Frio, Paraty e Rio de Janeiro.

A escolha destas localidades se deu pelo fato de pertencerem à Categoria $A$ do Mapa do Turismo Brasileiro, caracterizando-as por destinações que provem: o maior índice de empregos, de fluxos turísticos e de estabelecimentos hoteleiros (Brasil, 2016). Dito isso, o objetivo deste artigo consistiu em avaliar a percepção dos gestores de meios de hospedagem desses municípios quanto aos efeitos da economia compartilhada, do consumo colaborativo e das plataformas online de aluguel por temporada sobre os resultados de suas organizações. 


\section{ECONOMIA COMPARTILHADA E CONSUMO COLABORATIVO}

A prática da "economia compartilhada" se refere ao consumo colaborativo (CC) realizado em atividades de compartilhamento, troca ou aluguel de bens sem que haja, necessariamente, suas aquisições. Este exercício social se popularizou, nos últimos anos, devido ao compartilhamento de bens individuais tangíveis e intangíveis que se encontravam em ociosidade. A partir de seu compartilhamento, por meio de negociações consumer-to-consumer (C2C) e business-to-consumer (B2C) (Choi et al., 2014), promove-se um aproveitamento mais racional do excesso de bens e/ou produtos através do uso avançado da internet, do engajamento entre clientes e anfitriões e do oferecimento da proteção e da segurança entre esses pares (Mendes \& Ceroy, 2015).

Apesar de a EC ser vista como uma oportunidade para repensar a maneira como os modelos gerenciais contemporâneos ou os processos de tomada de decisão são realizados (Cheng, 2016b), em específico à cadeia produtiva do turismo, a EC acarreta mudanças significativas, ressaltando-se, por exemplo, a redução dos custos de hospedagem por meio da possibilidade de se estreitar laços socioculturais com a comunidade local (Cheng, 2016b). Já pelo ponto de vista da oferta turística, amplia seu leque de possibilidades, uma vez que empreendimentos fundamentados pelos princípios da EC necessitam de baixo investimento para iniciar suas operações (Nadler, 2014).

Cusumano (2015) enfatiza que a concretização da relação entre EC e turismo tornou-se possível devido à inserção dos startups - plataformas on-line -, que reúnem indivíduos que possuem ativos subutilizados e pessoas interessadas em alugá-los por curtos intervalos de tempo, promovendo o que Juul (2015) chamaria de inclusão social no turismo, uma vez que tais plataformas possibilitam o acesso a destinações e/ou atrativos turísticos que antes eram elitizados.

Assim, na visão do autor, tais instrumentos acabaram por se constituir em um novo grupo de concorrentes que, devido ao crescimento exponencial observado 
ISSN: 1983-7151

nos últimos anos, tornaram-se uma ameaça às empresas contemporâneas já estabelecidas. Nesse sentido, Cusumano (2015) salienta como aspecto imperativo a necessidade de as empresas tradicionais oferecerem serviços mais consistentes, confiáveis, qualitativos e seguros do que os ofertados pelos concorrentes da EC.

Boesler (2013) menciona que, em longo prazo, os efeitos deste sistema econômico podem ser catastróficos para as indústrias tradicionais, uma vez que prospectam um novo padrão de consumo - em que o ato da compra seria substituído pelo usufruto temporário de um bem, serviço ou produto - que exigiria mudanças nas estratégias, vendas, operações e até mesmo na estrutura organizacional. Atentos a essa nova configuração mercadológica que se desenha, os governos também se mostram preocupados com esse novo formato da atividade turística, uma vez que muitas dessas novas concepções infringem as regulamentações, tendo uma série de impactos sobre o direito do consumidor, da segurança e da qualidade (Juul, 2015; Cheng, 2016b).

Como exemplo, cita-se o Airbnb que, para Edelman e Geradin (2015), por uma perspectiva de longo prazo, pode acarretar uma ameaça à segurança do autóctone, ocasionando um forte problema de política habitacional. Apesar disso, alguns outros exemplos de negócios que despontaram com essa tendência são Uber, Spotify, Neflix e Bliive. A previsão, segundo economistas, é de que essa tendência seja responsável por movimentar o equivalente a $R \$ 1$ trilhão nos próximos anos (G1, 2015).

\section{CONSUMO COLABORATIVO NO SEGMENTO DE HOSPEDAGEM}

A primeira plataforma on-line a ganhar destaque com o modelo de negócios voltado para o CC de hospedagens foi a HomeAway. A empresa foi fundada em fevereiro de 2005 como um marketplace on-line para atender à indústria de aluguéis por temporada. Ao longo dos anos, muitas plataformas semelhantes foram adquiridas pela HomeAway e, em 2010, foi realizada a aquisição do AlugueTemporada, plataforma brasileira fundada em 2001 com o objetivo de auxiliar os viajantes na busca por imóveis para finais de semana, períodos de férias e feriados. 
Com anúncios de mais de um milhão de imóveis em 190 países, esse grupo americano se apresenta, em seu site, como o líder mundial em anúncios de imóveis para temporada e representa um concorrente direto do Airbnb (descrito a seguir). Somente no Brasil, são cerca de 20 mil imóveis anunciados e os acessos ao site ultrapassam os 20 milhões por ano (AlugueTemporada, 2015; Homeaway, 2015).

O Airbnb, por sua vez, foi idealizado no ano de 2007. Devido à realização de uma grande conferência de design na cidade de São Francisco (EUA), os hotéis ficaram lotados e o trio formado por Joe Gebbia, Brian Chesky e Nathan Blecharczyk decidiu, então, oferecer hospedagem e café da manhã, na própria casa, aos turistas que participariam do evento. No ano seguinte, a ideia se tornou um negócio, de fato, e, embora não tivesse tanto apelo para executivos e turistas mais abastados, começou a se popularizar entre os viajantes de perfil aventureiro e descolado, que buscavam economia em suas viagens e valorizavam a experiência de conhecer a rotina dos anfitriões (Exame, 2011).

O Airbnb, que funciona como um marketplace on-line, autodefine-se como um "website social que conecta pessoas que têm espaços sobrando às que estão procurando um lugar para ficar" (tradução livre) (Airbnb, 2015). Basicamente, potenciais anfitriões inscrevem seus imóveis na plataforma digital, definem o valor das diárias e, então, oferecem aos hóspedes (Zervas, Proserpio, \& Byers, 2015). O cadastro na plataforma é gratuito para os anunciantes. Em contrapartida, quando a reserva é efetivada, o Airbnb retém uma parcela dos valores envolvidos (Exame, 2011). Os hóspedes pagam uma taxa de serviço que varia de 9 a 12\% para cada reserva efetuada e os anfitriões, por sua vez, pagam uma taxa de $3 \%$ referente ao custos dos processos de pagamento (Zervas, Proserpio, \& Byers, 2015).

A plataforma teve rápido crescimento desde o seu lançamento em 2008 e, até o final de 2014, cerca de 30 milhões de usuários utilizaram seus serviços, sendo mais da metade (18 milhões) apenas no ano de 2013 (Zervas, Proserpio, \& Byers, 2015). Em abril de 2012, a empresa abriu um escritório no Brasil e colocou no ar a versão em português do site, uma vez que foi verificado aumento de mais de dez vezes nas receitas do Airbnb no país (Exame, 2013). Atualmente, 
o Airbnb está presente em 192 países e possui imóveis cadastrados em mais de 34 mil cidades, totalizando uma oferta de acomodações que ultrapassa um milhão de unidades (Airbnb, 2015). Vale citar também que, desde seu início, a empresa captou US\$826 milhões em capital de risco e possui valor de mercado de US\$ 10 bilhões - o que corresponde a 40 vezes a receita de US\$250 milhões estimada para o ano de 2013 (Cusumano, 2015).

A título de comparação, é importante salientar que as maiores redes de hotéis do mundo apresentam taxas de crescimento menores, valor de mercado relativamente menor comparado às suas receitas e quantidade de quartos também menor que o Airbnb. A rede de hotéis Marriott, por exemplo, possui cerca de 675 mil quartos em 74 países, obteve receita de US\$12,7 bilhões em 2013, e seu valor de mercado, em setembro de 2014, era de US\$ 20 bilhões. A rede Hilton, por sua vez, possui aproximadamente 679 mil quartos em 91 países, obteve receita de US\$ 9,7 bilhões, no ano de 2013, e seu valor de mercado em torno de US\$25 bilhões. Um terceiro exemplo é o grupo InterContinental que, com 674 quartos em 100 países, obteve receita de US\$1,9 bilhão, em 2013, e valor de mercado equivalente a US\$ 9 bilhões (ibidem).

$\mathrm{Na}$ maior parte dos destinos, o modelo de negócios do Airbnb opera sem grandes entraves regulatórios, o que facilita e aumenta as chances de fechamento de reservas. Além disso, para aumentar a confiança dos usuários e manter a boa reputação, o website conta com um sistema de avaliação pósestada, em que é incentivada a publicação de reviews pelos hóspedes, que classificam diferentes aspectos da hospedagem, como limpeza e localização (Zervas, Proserpio, \& Byers, 2015).

Mais recentemente, em 2014, o Hotel Urbano entrou no mercado de aluguel por temporada, lançando um portal chamado Voltem (www.voltem.com). O objetivo é similar ao das plataformas citadas anteriormente: conectar viajantes interessados em locar apartamentos, casas ou quartos por períodos curtos dos proprietários de imóveis. O portal oferece também a possibilidade de localizar opções de hospedagem em períodos de grandes eventos, como Rock in Rio, Fórmula 1 e Festa do Peão de Barretos. Segundo o fundador e CEO do Voltem, Eduardo Serrado, a expectativa é que a plataforma se consolide como a principal de aluguel por temporada do Brasil e da América Latina (Panrotas, 2014). 
Robson (2011) argumenta sobre a imperatividade de se fomentar nas análises científicas um olhar mais crítico, capaz de compreender a maneira como suas problemáticasseconstroeme/ousãoinfluenciadasporespecificidades, multiplicidades e heterogeneidades interdependentes observadas no "mundo real".

Justamente por isso, Robson (2011) menciona a necessidade de os acadêmicos entenderem as reais peculiaridades deste cenário. Assim, para que esse "desvendamento do mundo real" se efetive, uma série de precauções é necessária. Dentre essas, destaca-se o fato de os pesquisadores coetâneos se debruçarem não mais em aspectos puramente fixos/disciplinares, tal qual idealizado pelos pressupostos positivistas (Robson, 2011). De fato, torna-se preponderante "[...] encontrar modos de detectar - e não de ocultar - as ligações, articulações, solidariedades, implicações, imbricações, interdependências e complexidades do processo de conhecimento" (Oliveira \& Almeida, 2011, p.54).

Pautados nesses pressupostos, os autores deste artigo desenvolveram uma pesquisa quantitativa que permitiu garantir uma maior precisão e credibilidade de seus resultados, evitando quaisquer tipos de distorções (Creswell, 2003) em suas considerações. Por esse prisma, na tentativa de se testar a coerência conceitual e metodológica dessa amostragem (Singleton Jr. \& Straits, 2010), estruturou-se a seguinte hipótese:

- H1: Os gestores de meios de hospedagem percebem as plataformas de aluguel por temporada como uma ameaça aos seus negócios.

A partir desta prerrogativa, a pesquisa se dividiu em três etapas. A primeira compreendeu a definição do universo e da amostragem deste estudo, buscando estruturar um conhecimento científico a partir de núcleos aleatórios (Singleton Jr. \& Straits, 2010) que assegurassem a consistência, a coerência e a legibilidade dos discursos que aqui estão sendo propostos (Creswell, 2003). Dessa maneira, a amostra foi composta por gestores hoteleiros localizados nos municípios do Estado do Rio de Janeiro, pertencentes à categoria A do Mapa do Turismo Brasileiro. Nessa categoria, estão incluídos 51 municípios brasileiros, registrados pelo Ministério do 
ISSN: 1983-7151

Turismo como os que possuem o maior número de empregos, de estabelecimentos no segmento de hospedagem e o maior fluxo turístico. Em específico ao cenário fluminense, cinco municípios pertencem a essa categoria, a saber: Angra dos Reis, Armação dos Búzios, Cabo Frio, Paraty e Rio de Janeiro (Brasil, 2016).

Em uma segunda etapa, realizou-se uma pesquisa de campo, do tipo survey, para coleta de dados junto a essa amostragem. Seu instrumento de coleta consistiu em questionários semiestruturados que propiciaram, a partir da escala Likert de cinco pontos - 5-Concordo Plenamente, 4 - Concordo, 3 - Indiferente, 2 - Discordo, 1 - Discordo Plenamente -, inferências numéricas capazes de expor respostas concretas e diretas da problemática avaliada (Tashakkori \& Teddlie, 2010), ofertando uma análise estatística mais ágil e eficiente (Gil, 2008), capaz de indicar a intensidade das declarações prestadas (Gray, 2012)

Esse instrumento de coleta de dados composto por duas seções, em um primeiro momento limitou-se a obter informações sobre os respondentes e o estabelecimento aos quais estavam vinculados. Já em sua segunda seção, o intuito dos questionamentos apresentados era identificar a percepção dos respondentes quanto: às plataformas on-line de aluguel por temporada; ao CC; e à EC.

E, por fim, a terceira, e última etapa, consistiu na análise e no tratamento dos dados coletados. Para tanto, utilizou-se a técnica da estatística descritiva por meio da análise de frequências, assim como foi utilizada a moda - durante a interpretação dos dados - que representa o valor que ocorre com maior frequência (Anderson, Sweeney e Williams, 2009). Aspecto pertinente a ser reforçado aqui é o fato de a moda ter sido utilizada para apresentar as respostas que mais ocorrem na escala de concordância ordinal de Likert, empregada no desenvolvimento deste estudo.

\section{RESULTADOS E DISCUSSÕES}

A coleta dos dados consistiu no envio de um questionário, construído por meio do software SurveyMonkey, que é uma ferramenta on-line muito utilizada no meio acadêmico para pesquisas científicas. Este questionário foi enviado para um total de 506 e-mails relativos aos empreendimentos hoteleiros dos 
municípios de Angra dos Reis, Armação dos Búzios, Cabo Frio, Paraty e Rio de Janeiro. Estes e-mails foram disponibilizados pelo Ministério do Turismo, mediante solicitação, no dia 13 de novembro de 2015.

Osconvites, solicitandoaosgestoresdessesestabelecimentosqueparticipassem desta pesquisa, foram enviados para os e-mails no dia 29 de fevereiro de 2016. Após este primeiro disparo, outros dois lembretes foram enviados - nos dias 8 e 15 de março - aos gestores cujas respostas não haviam sido detectadas. Além deste procedimento, foram contatadas 11 entidades de classe (associações, sindicatos e secretarias) relacionadas ao segmento de hospedagem desses municípios, informando-Ihes sobre a pesquisa e seu propósito, solicitando-lhes auxílio na divulgação do link do questionário, que esteve disponível para preenchimento entre os dias 29 de fevereiro e 24 de março de 2016.

Dos 506 e-mails, obtiveram-se 46 respostas, gerando um percentual de $9,1 \%$. Somado a estas respostas, obtiveram-se 28 participações oriundas das entidades de classe dos municípios analisados, o que dá um montante final de 74 respondentes. No entanto, apenas 37 destas respostas foram absorvidas pela pesquisa - visto que as mesmas foram ofertadas por indivíduos que ocupavam cargos de gestão nos empreendimentos de hospedagem e com vasta experiência no mercado hoteleiro - tornando-se, portanto, a amostra considerada nesta pesquisa, uma vez que correspondia ao público-alvo de especialistas pretendido por este estudo.

\section{CARACTERIZAÇÃO DOS RESPONDENTES E DOS ESTABELECIMENTOS}

Vista como a primeira etapa do questionário semiestruturado, objetivou-se expor: localização, classificação, período em atividade, porte e quantificação de Unidades Habitacionais (UH's). Sobre suas localizações, a maior parte dos respondentes está localizada nos municípios do Rio de Janeiro e de Paraty, contabilizando 40,5\% e 37,9\% respectivamente. Armação dos Búzios e Angra dos Reis somam 8,1\% cada e Cabo Frio 5,4\%.

No que tange ao reconhecimento dos meios de hospedagem desses municípios, utilizou-se a proposta do Sistema Brasileiro de Classificação (SBClass) 
estruturada pelo Ministério do Turismo, que apresenta sete categorias, a saber: Hotel, Hotel Fazenda, Cama \& Café, Resort, Hotel Histórico, Pousada e Flat/ Apart-hotel (Brasil, 2010). Isto posto, nota-se a seguinte distribuição: 37,9\% são Pousadas; $21,6 \%$ são Hotéis; $5,4 \%$ são do tipo Cama \& Café; $2,7 \%$ são Flats/Apart-hotéis. Interessante notar a existência de outros empreendimentos que não se encaixam nas tipologias apresentadas pelo SBCLASS. Esses atingem uma representatividade de $32,4 \%$.

No que tange aos seus períodos de existências, os 37 meios de hospedagem analisados indicaram que suas atividades foram iniciadas em: menos que 1 ano - $0 \%$; entre 1 a 3 anos -21,6\%; entre 4 a 6 anos -27,1\%; entre 7 a 9 anos - 0\%; entre 10 a 15 anos - 13,5\%; entre 16 a 20 anos - 13,5\%; maior que 20 anos - 24,3\%. A partir destas descrições, detectaram-se: a maior concentração reside em empreendimentos com um posicionamento mercadológico entre 4 a 6 anos (27,1\%); a maioria desses estabelecimentos, 51,3\%, iniciou suas práticas a mais de 10 anos.

Sobre o porte do estabelecimento, averiguou-se que: 13,513\% microempreendedores individuais; 48,649\% eram microempresas; $35,135 \%$, de empresas de pequeno porte; $2,703 \%$, empresas de médio porte. É importante destacar que essa configuração reflete uma característica essencial do setor de turismo: o fato de sua composição ser estabelecida, em sua maior parte, por empreendimentos de porte menor (Brasil, 2015).

Finalmente, as questões 5 e 6 deste instrumento tiveram por objetivo quantificar o número UH's e de seus leitos. Desse modo, observou-se que esses respondentes possuem: até 10 UH's - 35,1\%; entre 11 a 30 UH's - 37,9\%; entre 31 a 50 UH's - 24,3\%; mais de 100 UH's - 2,7\%. Sobre a quantificação dos leitos, detectou-se que esses empreendimentos possuem: até 10 leitos - 5,4\%; entre 11 a 30 leitos - 21,7\%; entre 31 a 50 leitos - 32,4\%; entre 51 a 100 leitos - 32,4\%; mais de 100 leitos - 8,1\%.

\section{PERCEPÇÃO SOBRE CC, EC E PLATAFORMAS ON-LINE - ALUGUEL POR TEMPORADA}

As questões relativas à seção 2 do questionário buscaram avaliar a percepção dos gestores dos meios de hospedagem acerca das seguintes temáticas: plataformas on-line de aluguel por temporada, EC e CC. 
Ao indagá-los se possuíam conhecimento sobre alguma plataforma de aluguel por temporada, 25 gestores responderam que sim $(67,6 \%)$ e 12 responderam que não (32,4\%). Aos que responderam positivamente, o seguinte cenário pode ser apreendido: 01 gestor citou 04 plataformas; 10 gestores mencionaram 03 plataformas; 07 gestores referiram-se a 02 plataformas; 08 gestores apontaram 01 plataforma. Entre essas plataformas (Gráfico 1), a Airbnb (28,3\%), a Booking.com $(20,7 \%)$ e a AlugueTemporada (18,9\%) foram as que obtiveram maior frequência. Em sequência, fizeram-se menções à: TripAdvisor (9,4\%); Decolar.com (7,5\%); HostelWorld (5,7\%); Expedia, FlipKey, HomeAway, Trivago e Villas.com (1,9\% cada).

Gráfico 1. Reconhecimento de Plataformas Online - Aluguel por Temporada

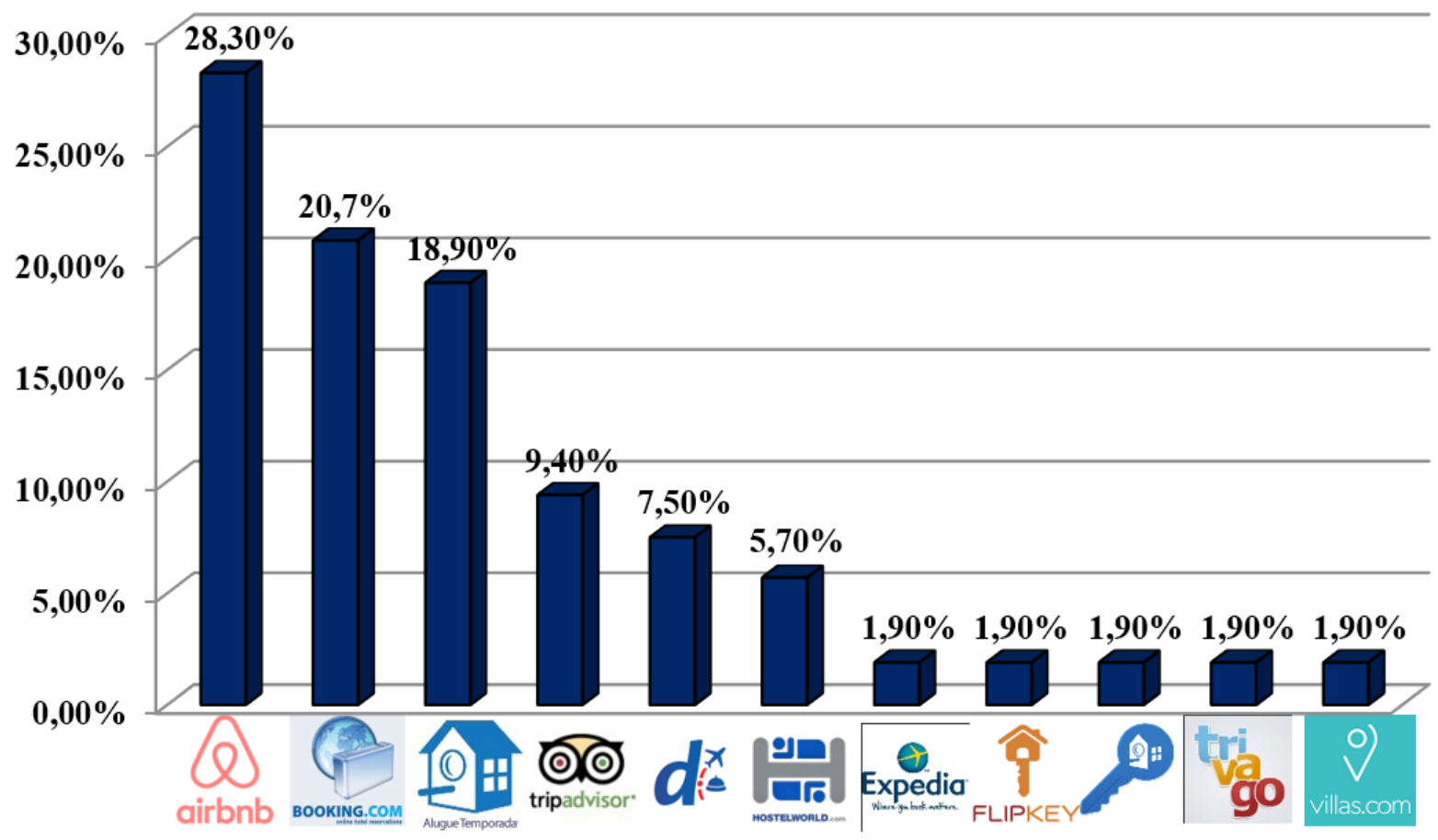

Fonte: Elaborado pelos autores.

$\mathrm{Na}$ tentativa de se aferir à percepção dos respondentes, foram apresentadas nove afirmações que apresentavam contextos pertinentes à temática deste trabalho. Para comentá-las, o gestor deveria assinalar sua percepção conforme a seguinte escala Likert: 5 - Concordo Plenamente (CP), 4 - Concordo (C), 3 Indiferente (I), 2 - Discordo (D), 1 - Discordo Plenamente (DP).

A Tabela 1 apresenta a distribuição das respostas dos respondentes, ilustrandoas com relação aos valores da escala Likert anteriormente apresentados. Dentre alguns aspectos que chamaram atenção, sendo esses destacados ao longo dessa tabela, enfatiza-se que: 
- 40,5\% dos entrevistados se mostraram indiferentes à afirmação B;

- $67,6 \%$ concordaram com a afirmação E (67,6\%);

- 35,1\% dos gestores se mostraram indiferentes à afirmação F.

A respeito do primeiro tópico, é interessante destacar que, apesar da indiferença verificada na resposta dos gestores, as atividades de compartilhamento impulsionadas pelo uso avançado da internet (como é o caso das plataformas online) são promotoras do aproveitamento mais racional de bens e produtos antes subutilizados (Mendes \& Ceroy, 2015). Além do mais, conforme argumenta Juul (2015), ao possibilitar aos viajantes o acesso a destinos anteriormente considerados elitizados, as plataformas promovem também a inclusão social no turismo.

Quanto à afirmação $E$, em que foi verificado alto grau de concordância por parte dos gestores dos meios de hospedagem, percebe-se também uma coerência em relação ao que é apresentado na literatura, uma vez que os benefícios econômicos são igualmente mencionados como um dos principais fatores motivadores nas atividades de compartilhamento (Hamari, Sjöklint \& Ukkonen, 2015).

Outro aspecto que vale ser destacadoé a neutralidade observada nas respostas dos gestores quanto à ameaça que as plataformas poderiam representar aos seus estabelecimentos - Afirmação F. Verifica-se que esta percepção apresenta certa divergência quando comparada com afirmações de Cusumano (2015) e Boesler (2013). Para tais autores, para que as empresas tradicionais possam enfrentar os desafios decorrentes da expansão das atividades de compartilhamento e, assim, se manterem competitivas, será indispensável a oferta de serviços confiáveis e superiores aos que são apresentados pelos negócios emergentes da EC.

Tabela 1. Distribuição de frequência das afirmações

\begin{tabular}{|c|c|c|c|c|c|}
\hline \multirow{2}{*}{ AFIRMAÇÕES } & \multicolumn{4}{|c|}{ GRAU DE CONCORDÂNCIA } \\
\cline { 2 - 5 } & $5-$ CP & $4-$ C & $3-$ I & 2 - D & 1 - DP \\
\hline $\begin{array}{c}\text { A - Os governantes devem apoiar o } \\
\text { progresso de plataformas desse tipo. }\end{array}$ & $8,1 \%$ & $16,2 \%$ & $43,2 \%$ & $18,9 \%$ & $13,5 \%$ \\
\hline $\begin{array}{c}\text { B - As plataformas podem contribuir } \\
\text { para melhorar a crise econômica e o } \\
\text { aquecimento global. }\end{array}$ & $10,8 \%$ & $21,6 \%$ & $40,5 \%$ & $5,4 \%$ & $21,6 \%$ \\
\hline
\end{tabular}


Dor: 10.14210/rtva.v19n3.p658-683

\begin{tabular}{|c|c|c|c|c|c|}
\hline $\begin{array}{c}\text { C - As empresas precisam se adaptar } \\
\text { às mudanças do mercado pensar em } \\
\text { novas formas de gerar receita. }\end{array}$ & $37,8 \%$ & $45,9 \%$ & $10,8 \%$ & $2,7 \%$ & $2,7 \%$ \\
\hline $\begin{array}{c}\text { D - Os consumidores agora podem } \\
\text { dispensar os produtos e os serviços das } \\
\text { empresas tradicionais. }\end{array}$ & $5,4 \%$ & $13,5 \%$ & $24,3 \%$ & $40,5 \%$ & $16,2 \%$ \\
\hline $\begin{array}{c}\text { E - Os benefícios econômicos são a } \\
\text { principal motivação para a participação } \\
\text { em atividades de compartilhamento de } \\
\text { bens e serviços. }\end{array}$ & $5,4 \%$ & $67,6 \%$ & $21,6 \%$ & $5,4 \%$ & $0,0 \%$ \\
\hline $\begin{array}{c}\text { F - As plataformas representam uma } \\
\text { ameaça às empresas já estabelecidas. }\end{array}$ & $8,1 \%$ & $18,9 \%$ & $35,1 \%$ & $32,4 \%$ & $5,4 \%$ \\
\hline $\begin{array}{c}\text { G - Os consumidores preferem pagar } \\
\text { para ter acesso a produtos e serviços } \\
\text { temporariamente (sem a necessidade } \\
\text { de comprá-los). }\end{array}$ & $13,5 \%$ & $37,8 \%$ & $37,8 \%$ & $10,8 \%$ & $0,0 \%$ \\
\hline
\end{tabular}

Tabela 1. Distribuição de frequência das afirmações (Continuação).

\begin{tabular}{|c|c|c|c|c|c|}
\hline \multirow{2}{*}{ AFIRMAÇÕES } & \multicolumn{5}{|c|}{ GRAU DE CONCORDÂNCIA } \\
\cline { 2 - 6 } & $5-$ CP & $4-$ C & $3-$ I & 2 - D & 1 - DP \\
\hline $\begin{array}{c}\text { H - Existe competição entre as } \\
\text { plataformas e os negócios tradicionais. }\end{array}$ & $24,3 \%$ & $35,1 \%$ & $27,0 \%$ & $10,8 \%$ & $2,7 \%$ \\
\hline $\begin{array}{c}\text { I - As plataformas beneficiam os } \\
\text { consumidores que estão à procura de } \\
\text { maior conveniência e menor preço. }\end{array}$ & $21,6 \%$ & $40,5 \%$ & $27,0 \%$ & $8,1 \%$ & $2,7 \%$ \\
\hline
\end{tabular}

Fonte: Elaborada pelos autores.

Infere-se, a partir da constituição dessa Tabela 1, o seguinte cenário analítico perante a maioria dos respondentes: existe concordância em cinco proposições ( $C, E, G, H$ e I), o que permite estabelecer uma moda igual a 4, ou seja, a maioria dos respondentes optaram pelo grau de concordância igual a 4; há indiferença com relação a quatro afirmações ( $A, B, F$ e $G)$, o que possibilita o alcance de uma moda igual a 3; e, por fim, houve discordância com relação à afirmativa $D$, o que proporcionou um moda igual a 2. Não obstante, julga-se relevante salientar que a afirmação G - "Os consumidores preferem pagar para ter acesso a produtos e serviços temporariamente (sem a necessidade de comprá-los)" é bimodal, uma vez que ocorreram as mesmas representatividades para as escalas $4-\mathrm{C}$ e 3 - I.

No que diz respeito à discordância dos gestores em relação à afirmação $D$, vale trazer a reflexão de Goel (2014) sobre a restauração do poder dos consumidores. O autor salienta que a possibilidade de os consumidores se conectarem a outros indivíduos sem necessidade de intermediários cria uma nova realidade mercadológica que impacta significativamente o sistema capitalista e exige das 
empresas uma adaptação imprescindível às mudanças. É interessante observar que tais argumentos, embora tenham sido, de certa forma, refutados pelos gestores na afirmação $D$, possuem uma pertinente correlação às afirmações $C$ e $F$, que apresentaram maior grau de concordância.

Sobre a percepção gerada em cada um dos municípios - Angra dos Reis, Armação dos Búzios, Cabo Frio, Paraty e Rio de Janeiro - sobre essas afirmativas, a Tabela 2 apresentará suas distinções.

Tabela 2. Distribuição de frequência das afirmações por município

\begin{tabular}{|c|c|c|c|c|c|c|c|c|c|c|c|c|c|c|c|}
\hline \multirow{3}{*}{ AFIRMAÇÕES } & \multicolumn{15}{|c|}{ GRAU DE CONCORDÂNCIA (em \%) } \\
\hline & \multicolumn{5}{|c|}{$5-C P$} & \multicolumn{5}{|c|}{$4-C$} & \multicolumn{5}{|c|}{$3-I$} \\
\hline & $A R$ & $A B$ & CF & PY & RJ & $A R$ & $A B$ & CF & PY & RJ & AR & $A B$ & $\mathrm{CF}$ & PY & RJ \\
\hline $\begin{array}{c}\text { A - Os governantes } \\
\text { devem apoiar } \\
\text { o progresso de } \\
\text { plataformas desse } \\
\text { tipo. }\end{array}$ & 0 & 33,3 & 0 & 7,1 & 6,7 & 33,3 & 0 & 0 & 21,4 & 13,3 & 33,3 & 0 & 50 & 42,9 & 53,3 \\
\hline $\begin{array}{c}\text { B - As plataformas } \\
\text { podem contribuir } \\
\text { para melhorar a } \\
\text { crise econômica } \\
\text { e o aquecimento } \\
\text { global. }\end{array}$ & 0 & 33,3 & 0 & 7,1 & 13,3 & 33,3 & 0 & 0 & 28,6 & 20 & 66,7 & 0 & 50 & 35,7 & 46,7 \\
\hline $\begin{array}{l}\text { C - As empresas } \\
\text { precisam se } \\
\text { adaptar às } \\
\text { mudanças do } \\
\text { mercado e pensar } \\
\text { em novas formas } \\
\text { de gerar receita. }\end{array}$ & 66,7 & 33,3 & 50 & 14,3 & 53,3 & 33,3 & 33,3 & 0 & 71,4 & 33,3 & 0 & 0 & 50 & 7,1 & 13,3 \\
\hline $\begin{array}{c}\text { D - Os } \\
\text { consumidores } \\
\text { agora podem } \\
\text { dispensar os } \\
\text { produtos e } \\
\text { os serviços } \\
\text { das empresas } \\
\text { tradicionais. }\end{array}$ & 0 & 33,3 & 0 & 0 & 6,7 & 0 & 33,3 & 0 & 0 & 26,7 & 100 & 0 & 50 & 14,3 & 20 \\
\hline $\begin{array}{l}\text { E - Os benefícios } \\
\text { econômicos são a } \\
\text { principal motivação } \\
\text { para a participação } \\
\text { em atividades de } \\
\text { compartilhamento } \\
\text { de bens e serviços. }\end{array}$ & 0 & 0 & 0 & 7,1 & 6,7 & 66,7 & 100 & 50 & 64,3 & 66,7 & 0 & 0 & 50 & 28,6 & 20 \\
\hline $\begin{array}{c}\text { F - As plataformas } \\
\text { representam } \\
\text { uma ameaça } \\
\text { às empresas já } \\
\text { estabelecidas. }\end{array}$ & 0 & 33,3 & 0 & 14,3 & 0 & 0 & 0 & 50 & 7,1 & 33,3 & 100 & 0 & 50 & 28,6 & 33,3 \\
\hline
\end{tabular}




\begin{tabular}{|c|c|c|c|c|c|c|c|c|c|c|c|c|c|c|c|}
\hline $\begin{array}{c}\text { G - Os } \\
\text { consumidores } \\
\text { preferem pagar } \\
\text { para ter acesso a } \\
\text { produtos e serviços } \\
\text { temporariamente } \\
\text { (sem a necessidade } \\
\text { de comprá-los). } \\
\end{array}$ & 33,3 & 0 & 0 & 7,1 & 20 & 33,3 & 33,3 & 50 & 28,6 & 46,7 & 33,3 & 33,3 & 50 & 50,0 & 26,7 \\
\hline $\begin{array}{c}\mathbf{H} \text { - Existe } \\
\text { competição entre } \\
\text { as plataformas } \\
\text { e os negócios } \\
\text { tradicionais. }\end{array}$ & 0 & 100 & 0 & 28,6 & 13,3 & 33,3 & 0 & 50 & 35,7 & 40 & 66,7 & 0 & 50 & 21,4 & 26,7 \\
\hline $\begin{array}{l}\text { I - As plataformas } \\
\text { beneficiam os } \\
\text { consumidores que } \\
\text { estão à procura de } \\
\text { maior conveniência } \\
\text { e menor preço. }\end{array}$ & 0 & 33,3 & 50 & 14,3 & 26,7 & 33,3 & 33,3 & 50 & 57,1 & 26,7 & 66,7 & 0 & 0 & 21,4 & 33,3 \\
\hline \multirow{3}{*}{\multicolumn{6}{|c|}{ AFIRMAÇÕES }} & \multicolumn{10}{|c|}{ GRAU DE CONCORDÂNCIA (em \%) } \\
\hline & & & & & & \multicolumn{5}{|c|}{$2-D$} & \multicolumn{5}{|c|}{$1-D P$} \\
\hline & & & & & & $A R$ & $A B$ & $C F$ & PY & RJ & $A R$ & $A B$ & CF & PY & RJ \\
\hline \multicolumn{6}{|c|}{$\begin{array}{c}\text { A - Os governantes devem apoiar o progresso } \\
\text { de plataformas desse tipo. }\end{array}$} & 33,3 & 0 & 50 & 14,3 & 20 & 0 & 66,7 & 0 & 14,3 & 6,7 \\
\hline \multicolumn{6}{|c|}{$\begin{array}{c}\text { B - As plataformas podem contribuir para } \\
\text { melhorar a crise econômica e aquecimento } \\
\text { global. }\end{array}$} & 0 & 0 & 50 & 7,1 & 0 & 0 & 66,7 & 0 & 21,4 & 20 \\
\hline \multicolumn{6}{|c|}{$\begin{array}{l}\text { C - As empresas precisam se adaptar às } \\
\text { mudanças do mercado e pensar em novas } \\
\text { formas de gerar receita. }\end{array}$} & 0 & 33,3 & 0 & 0 & 0 & 0 & 0 & 0 & 7,1 & 0 \\
\hline \multicolumn{6}{|c|}{$\begin{array}{c}\text { D - Os consumidores agora podem dispensar } \\
\text { os produtos e serviços das empresas } \\
\text { tradicionais. }\end{array}$} & 0 & 33,3 & 50 & 64,3 & 26,7 & 0 & 0 & 0 & 21,4 & 20 \\
\hline \multicolumn{6}{|c|}{$\begin{array}{l}\text { E - Os benefícios econômicos são a principal } \\
\text { motivação para a participação em atividades } \\
\text { de compartilhamento de bens e serviços. }\end{array}$} & 33,3 & 0 & 0 & 0 & 0 & 0 & 0 & 0 & 0 & 6,7 \\
\hline \multicolumn{6}{|c|}{$\begin{array}{l}\text { F - As plataformas representam uma ameaça } \\
\text { às empresas já estabelecidas. }\end{array}$} & 0 & 66,7 & 0 & 50 & 20 & 0 & 0 & 0 & 0 & 13,3 \\
\hline \multicolumn{6}{|c|}{$\begin{array}{c}\text { G - Os consumidores preferem pagar } \\
\text { para ter acesso a produtos e serviços } \\
\text { temporariamente (sem a necessidade de } \\
\text { comprá-los). }\end{array}$} & 0 & 33,3 & 0 & 14,3 & 0 & 0 & 0 & 0 & 0 & 6,7 \\
\hline \multicolumn{6}{|c|}{$\begin{array}{l}\text { H - Existe competição entre as plataformas e } \\
\text { os negócios tradicionais. }\end{array}$} & 0 & 0 & 0 & 14,3 & 13,3 & 0 & 0 & 0 & 0 & 6,7 \\
\hline \multicolumn{6}{|c|}{$\begin{array}{l}\text { I - As plataformas beneficiam os } \\
\text { consumidores que estão à procura de maior } \\
\text { conveniência e menor preço. }\end{array}$} & 0 & 33,3 & 0 & 7,1 & 6,7 & 0 & 0 & 0 & 0 & 6,7 \\
\hline
\end{tabular}

Partindo-se de uma perspectiva macro, há a possibilidade de se notar que:

- A maior parte das respostas concentrou-se na Escala 4, gerando uma concordância acerca das descrições apresentadas pelas afirmações; 
- Todos os gestores, independentemente de sua localização:

- Concordam que "os benefícios econômicos são a principal motivação para a participação em atividades de compartilhamento de bens e serviços";

- Discordam plenamente acerca das descrições apresentadas entre as sentenças $\mathrm{C}$ a I.

- Os gestores de $A R, A B, C F$ e RJ concordam plenamente que "as empresas precisam se adaptar às mudanças do mercado e pensar em novas formas de gerar receita";

- Nota-se a existência de uma dubiedade entre os gestores de $A R, A B$ e $C F$, visto que os mesmos concordam ou acham indiferente o fato de que "os consumidores preferem pagar para ter acesso a produtos e serviços temporariamente (sem a necessidade de comprá-los)";

- Os gestores de $A B, C F, P Y$ e RJ acham indiferente o fato de que "as plataformas podem contribuir para melhorar a crise econômica e aquecimento global";

- Os gestores de $A B, C F, P Y$ e RJ discordam que "os consumidores agora podem dispensar os produtos e serviços das empresas tradicionais", sendo que os gestores de AR se mostram indiferentes a essa perspectiva;

- Em nenhum momento os gestores de $A R, C F, P Y$ e RJ discordaram plenamente das afirmações.

Por perspectivas individuais, observando o posicionamento micro dos resultados apontados pela Tabela 2, observa-se que os gestores dos meios de hospedagem situados em Angra dos Reis manifestaram os seguintes posicionamentos sobre as afirmativas de A até I: B, H e I expõem a Escala 3 (I) como maior notoriedade $(66,7 \%)$, ocasionando uma moda igual a 3 ; C apresenta a Escala 5 (CP), com 66,7\%, estabelecendo uma moda igual a 5; D e F proporcionam a Escala 3 (I), com 100\%, estabelecendo uma moda igual a 3; E exibe a Escala 4 (C), com 66,7\%, estabelecendo uma moda igual a 4.

Já Armação dos Búzios propicia as seguintes descrições: A e B trazem a Escala 1 (DP) como generalização de suas percepções (66,7\%), estabelecendo 
uma moda igual a 1; E proporciona a Escala 4 (C), com 100\%, estabelecendo uma moda igual a 4; F apresenta a Escala 2 (D), com 66,7\%, estabelecendo uma moda igual a 2; $\mathrm{H}$ proporciona a Escala 5 (CP), com $100 \%$, estabelecendo uma moda igual a 5 . Sobre o município de Cabo Frio, devido à quantidade reduzida de respondentes e aparentes divergências na avaliação das afirmações, estas apresentaram caráter bimodal.

Para Paraty fora possível aferir o seguinte cenário: 42,9\%, 35,7\% e 50\% dos gestores acham indiferentes as afirmações $A, B$ e $G$, respectivamente, estabelecendo uma moda igual a 3; 71,4\%, 64,3\%, 35,7\% e 57,1\% dos entrevistados concordam - Escala 4 (C) - com os preceitos estabelecidos pelas sentenças $\mathrm{C}, \mathrm{E}, \mathrm{H}$ e I, respectivamente, proporcionando-Ihes uma média igual a $4 ; 64,3 \%$ e $50 \%$ dos respondentes discordam - Escala 2 (D) - das proposições expostas pelas narrativas D e F, dando-lhes uma média igual a 2 .

E, finalmente, os gestores dos meios de hospedagem localizados no município do Rio de Janeiro ofertaram as seguintes percepções: 53,3\%, 46,7\%, $33,3 \%$ dos gestores acham indiferentes as afirmações A, B e I, respectivamente, estabelecendo uma moda igual a $3 ; 53,3 \%$ dos entrevistados concordam plenamente - Escala 5 (CP) - com a afirmação C, ofertando-lhe uma média igual a $5 ; 66,7 \%$ e $46,7 \%$ dos respondentes concordam - Escala 4 (C) - propiciandoIhe uma média igual a 4.

No que tange às possíveis estratégias a serem empregadas para minimizar os efeitos negativos da EC e do CC perante os resultados organizacionais e a competitividade desses estabelecimentos, destacam-se:

(1) um maio rigor sobre a estruturação do planejamento financeiro e do controle de custos do empreendimento. Pelo fato de a competitividade e de os resultados organizacionais serem afligidos pela entrada de novos players, este posicionamento se torna essencial para que não haja o comprometimento da viabilidade do negócio (Bordean \& Borza, 2014);

(2) um controle mais eficaz da qualidade dos produtos, dos serviços e dos atendimentos ofertados, de maneira que se exalte a larga diferença entre os escopos operacionais e estruturais de um imóvel registrado nessas plataformas on-line de aluguel por temporada e de um meio de hospedagem (Poon, 1994; Buhalis, 2001; Ekiyor, 2011; Bordean \& Borza, 2014); 
(3) o entrelace da imagem e da marca organizacional aos preceitos da qualidade percebida (Dimmock, 1999; Ekiyor, 2011; Bordean \& Borza, 2014), garantindo a proposição de uma estrutura organizacional - completamente distinta à oferecida pelas plataformas on-line que prime pela contínua e ininterrupta inovação de seus produtos, serviços, infraestruturas e equipamentos. Aspecto esse que permite a promoção de um ambiente flexível, dinâmico e apto a atender distintos desejos, necessidades e expectativas de sua clientela (Dimmock, 1999; Bordean \& Borza, 2014).

Vale mencionar também que o uso de mídias sociais é imprescindível no novo cenário econômico, em que cresce a importância da internet para os negócios de turismo e da manutenção de uma boa reputação on-line. Portanto, o alinhamento das empresas às novidades e às tendências tecnológicas revela-se como uma estratégia necessária para aumentar a visibilidade do negócio (com custos reduzidos de divulgação) e, consequentemente, a taxa de ocupação dos meios de hospedagem (Eraqi, 2005; Munteanu, Rizea, Ilie \& Sarbu, 2014).

\section{CONSIDERAÇÕES FINAIS}

O fenômeno recente da EC trouxe significativas mudanças mercadológicas, especialmente no que diz respeito ao comportamento dos consumidores. Com a emergência de novas tecnologias, tornou-se mais fácil o compartilhamento de bens individuais ociosos e observou-se o surgimento de diversas plataformas digitais criadas com o intuito de promover o CC.

Diferentes setores foram impactados por esse novo padrão de consumo, caracterizado pela priorização do compartilhamento de bens em detrimento da propriedade. No setor de turismo, verificou-se que novos modelos de negócios surgiram nesse contexto, como as plataformas on-line de aluguel por temporada, que conectam anfitriões e potenciais hóspedes, podendo representar uma ameaça aos meios de hospedagem tradicionais.

Tendo em vista que essas plataformas podem não somente apresentar vantagem competitiva frente aos empreendimentos já existentes, mas também modificar a lógica da competição no setor, no presente trabalho se buscou investigar como o CC de hospedagem é percebido pelos gestores de meios de 
hospedagem de cinco municípios do Estado do Rio de Janeiro. Os resultados obtidos a partir da aplicação de um questionário de pesquisa permitiram mapear o entendimento dos gestores quanto ao fenômeno da EC, do CC e das plataformas on-line de aluguel por temporada.

Tendo como base as modas identificadas, observou-se que, dentre as nove afirmações citadas no questionário, cinco foram validadas pelos gestores que responderam. Foram elas:

As plataformas beneficiam os consumidores que estão à procura de maior conveniência e menor preço;

- Existe competição entre as plataformas e os negócios tradicionais;

- Os consumidores preferem pagar para ter acesso a produtos e serviços temporariamente (sem a necessidade de comprá-los);

- Os benefícios econômicos são a principal motivação para a participação em atividades de compartilhamento de bens e serviços; e

- As empresas precisam se adaptar às mudanças do mercado e pensar em novas formas de gerar receita.

É válido salientar que a necessidade de adaptação das empresas às mudanças do mercado foi apontada como a afirmação que obteve maior grau de concordância por parte dos gestores, seguida pela afirmação que cita os benefícios econômicos como a principal motivação para a participação em atividades de compartilhamento de bens e serviços.

Verificou-se também que três das afirmações com as quais os gestores concordaram fazem alusão a questões econômico-financeiras, que, conforme avaliação dos mesmos, representam um aspecto relevante quanto às plataformas on-line e ao contexto da EC e do CC.

Merece destaque também a afirmação que trata da competição entre as plataformas e os negócios tradicionais, especialmente porque a amostra deste trabalho foi composta, predominantemente, por micro e pequenos empreendimentos e porque este resultado valida a hipótese deste trabalho. A 
avaliação dos gestores, ao revelar que as plataformas on-line são percebidas como uma ameaça à competitividade dos seus negócios, pode indicar que, nestes empreendimentos, as estratégias de segmentação ou de diferenciação não estão bem-definidas ou são inexistentes. Consequentemente, estes não conseguem gerar valor superior ao que é oferecido pelos proprietários de imóveis nas plataformas e, portanto, passam a concorrer com estes novos entrantes.

As demais afirmações foram avaliadas de forma indiferente ou não apresentaram nenhum grau de concordância por parte dos gestores.

Tendo em vista que as afirmações contidas no questionário são provenientes da revisão de literatura sobre o tema, esse resultado pode revelar dois fatos distintos. O primeiro refere-se ao entendimento parcial dos respondentes quanto à $\mathrm{EC}$, ao $\mathrm{CC}$ e às plataformas on-line de aluguel por temporada. Por outro lado, este mesmo resultado pode também indicar que apenas parte do que é reportado na literatura foi percebido pelos gestores de meios de hospedagem.

É importante lembrar que o presente estudo possui limitações que não permitem o mapeamento pleno dos efeitos sentidos no segmento de hospedagem do Estado do Rio de Janeiro e, consequentemente, da percepção dos gestores envolvidos. Não obstante, buscou-se contribuir para um maior entendimento sobre o fenômeno recente da EC e do CC.

Recomenda-se que outros estudos sejam conduzidos, futuramente, não apenas sobre os temas abordados neste artigo, mas também sobre temáticas relacionadas, por exemplo, o perfil dos consumidores que optam por contratar serviços de hospedagem por meios das plataformas on-line em detrimento dos meios de hospedagem tradicionais, os impactos econômicos experimentados pelos destinos turísticos em que as plataformas de aluguel por temporada possuem maior mercado consumidor, os benefícios à sustentabilidade promovidos pelo compartilhamento de bens ociosos, entre outros. Desse modo, haverá maior clareza quanto às mudanças sentidas no setor de turismo e maior será a possibilidade de as empresas encontrarem alternativas para enfrentar os desafios dos novos tempos. 
Airbnb. (2016). Quem somos. Recuperado em 15 outubro, 2016, de: https://www.airbnb. com.br/about/about-us.

Anderson, D. R., Sweeney, D. J., Willians, T. Estatística aplicada à administração e economia. São Paulo: Pioneira, 2009.

Bardhi, F. \& Eckhardt, G. M. (2012). Access-based consumption: The case of car sharing. Journal of Consumer Research, 39(4), 881-898. DOI: 10.1086/666376

Boesler, M. (2013, Agosto 12). The rise of the renting and sharing economy could have catastrophic ripple effects. Business Insider. Retrieved October 25, 2016 from: http://www. businessinsider.com/rise-of-the-renting-and-sharing-economy-2013-8?op=1.

Bordean, O. N. \& Borza, A. (2014). Strategic management practices within the Romanian hotel industry. Amfiteatru Economic, 16(8), 1238-1252. DOI: 10.13140/2.1.4282.2081

Botsman, R. \& Rogers, R. (2011). O que é meu é seu: Como o consumo coletivo está mudando o nosso mundo. Porto Alegre, RS: Bookman.

Brasil. Ministério do Turismo. (2010). Cartilha de Orientação Básica - Sistema Brasileiro de Classificação de Meios de Hospedagem. Recuperado em 13 dezembro, 2016 de: http://www. classificacao.turismo.gov.br/MTUR-classificacao/mtur-site/downloadCartilha.action?tipo=1.

Brasil. Ministério do Turismo. (2015). Pequenos negócios movimentam o turismo no Brasil. Recuperado em 13 dezembro, 2016 de: http://www.turismo.gov.br/\%C3\%BAltimasnot\%C3\%ADcias/5143-pequenos-negocios-movimentam-o-turismo-no-brasil.html.

Brasil. Ministério do Turismo. (2016). Categorização dos municípios das regiões turísticas do Mapa do Turismo Brasileiro. Recuperado em 05 dezembro, 2016 de: http://www.turismo. gov.br/sem-categoria/5854-categoriza\%C3\%A7\%C3\%A3o-dos-munic\%C3\%ADpios-dasregi\%C3\%B5es-tur\%C3\%ADsticas-do-mapa-do-turismo-brasileiro.html.

Buhalis, D. (2001). Tourism in Greece: strategic analysis and challenges. Current Issues in Tourism, 4(5), 440-480. DOI: 10.1080/13683500108667898

Ceroy, F. M. (2015). Uber e Netflix são a ponta do iceberg da economia compartilhada. IDGNow. Recuperado em 13 dezembro, 2016 de: http://idgnow.com.br/internet/2015/07/06/ artigo-uber-e-netflix-sao-a-ponta-do-iceberg-da-economia-compartilhada.

Cheng, M. (2016a). Current sharing economy media discourse in tourism. Annals of Tourism Research, 60(C), 111-114. DOI: 10.1016/j.annals.2016.07.001 
Cheng, M. (2016b). Sharing economy: A review and agenda for future research. International Journal of Hospitality Management, 57, 60-70. DOI: 10.1016/j.jjhm.2016.06.003

Choi, H. R., Cho, M. J., Lee, K.; Hong, S. G. \& Wo, C. R. (2014). The business model for the sharing economy between SMEs. WSEAS Transactions on Business and Economics, 11(1), 625-634.

Christensen, C. M. (2001). O dilema da inovação (vol. 261). São Paulo, SP: Makron Books.

Creswell, J. W. (2003). Research design: Qualitative, quantitative and mixed methods approaches. Thousand Oaks: Sage Publications, Inc.

Cusumano, M. A. (2015, Janeiro). Technology strategy and management: How traditional firms must compete in the sharing economy. Communications of the ACM, 58(1), 32-34. DOI: $10.1145 / 2688487$

Dimmock, K. (1999). Management style and competitive strategies among tourism firms in the Northern Rivers. Tourism Management, 20(3), 323-339. DOI: 10.1016/S02615177(98)00119-8

Edelman, B.G. \& Geradin, D. (2015). Efficiencies and regulatory shortcuts: how should we regulate companies like Airbnb and Uber? Forthcoming, Stanford Technology Law Review.

Ekiyor, A. (2011). Strategies boutique hotel in and around the city of Izmir in gaining competitive superiority. World Applied Sciences Journal, 12(11), 2005-2005. Retrieved November 13, 2016 from: http://idosi.org/wasj/wasj12(11)/12.pdf

Eraqi, M. I. (2005) IT as a means for enhancing competitive advantage. Anatolia: An International Journal of Tourism and Hospitality Research, 16(2), xx-xx. DOI: 10.1080/13032917.2006.9687025

Exame (2011, Maio 31). Airbnb, uma startup de US\$1 bilhão. Recuperado em 17 outubro, 2016de: http://exame.abril.com.br/pme/noticias/airbnb-uma-startup-de-us-1-bilhao

Exame (2013, Março 25). Airbnb oferece todo o tipo de aluguéis para viajantes. Recuperado em 05 setembro, 2016 de: http://exame.abril.com.br/revista-exame-pme/edicoes/58/ noticias/airbnb-oferece-todo-o-tipo-de-alugueis-para-viajantes

Fremstad, A. (2014). Gains from sharing: Sticky norms, endogenous preferences, and the economics of shareable goods. Economics Department Working Paper Series, paper 168, 1-32.

G1. Jornal Nacional. (2015). Compartilhar serviços e produtos vira tendência entre consumidores. Recuperado em 21 novembro, 2016 de: http://g1.globo.com/jornalnacional/noticia/2015/07/compartilhar-servicos-e-produtos-vira-tendencia-entreconsumidores.html. 
Gil, A. C. (2008). Métodos e técnicas de pesquisa social. São Paulo, SP: Atlas.

Goel, S. (2014). Capitalism versus the sharing economy. UC Berkeley: UC Berkeley Library. Recuperado em 12 fevereiro, 2016 de: http://www.escholarship.org/uc/item/8xd4m19w

Gray, D. E. (2012). Pesquisa no mundo real. Porto Alegre, RS: Penso.

Hamari, J.; Sjöklint, M.; Ukkonen, A. (2015). The sharing economy: why people participate in collaborative consumption. Journal of the Association for Information Science and Technology, 67(9), 2047-2059. Recuperado em 12 fevereiro, 2016 de: http://www.ssrn.com/ abstract $=2271971$

Juul, M. (2015). The sharing economy and tourism. Retrieved September 19, 2016 from: http://www.europarl.europa.eu/RegData/etudes/BRIE/2015/568345/ EPRS_BRI(2015)568345_EN.pdf.

Matzler, K., Veider, V. \& Kathan, W. (2015). Adapting to the sharing economy. MIT Sloan Management Review, 56(2), 71-77.

Mendes, F. S. \& Ceroy, F. M. (2015). Economia compartilhada e a Política Nacional de Mobilidade Urbana: Uma proposta de marco legal. Brasília, DF: Núcleo de Estudos e Pesquisas/CONLEG/Senado.

Munteanu, A. R., Rizea, R. D., Ilie, A. G. \& Sarbu, R. (2014). Investigating Potential Strategies for Increasing Tourism Competitiveness at the Black Sea Shore. Amfiteatru Economic, 16(8), 1253-1286. Retrieved December 10, 2016 from: http://www.amfiteatrueconomic.ro/temp/ Article_1353.pdf

Nadler, S. S. N. (2014). The sharing economy: What is it and where is it going? Massachusetts: Institute of Technology.

Oliveira, M. R. \& Almeida, J. (2011). Programas de pós-graduação interdisciplinares: Contexto, contradições e limites do processo de avaliação Capes. Revista Brasileira de Pós-Graduação, 8(15), 37-57. DOI: 10.21713/2358-2332.2011.8.210

Panrotas (2014, Dezembro 9). Hotel Urbano lança site de aluguel por temporada. Recuperado em 24 novembro, 2016 de: http://www.panrotas.com.br/noticia-turismo/mercado/2014/12/ hotel-urbano-lanca-site-de-aluguel-por-temporada_108269.html.

Poon, A. (1994). The 'new tourism' revolution. Tourism Management, 15(2), 91-92. doi: 10.1016/0261-5177(94)90001-9

Quinson, E. (2015). Collaborative consumption through new technologies. Centria University of Applied Sciences. 
Robson, C. (2011). Real world research design: A resource for users of social research methods in applied settings. West Sussex: John Wiley \& Sons, Ltd.

Schor, J. (2014). Debating the sharing economy. Retrived October 13, 2016 from: http:// greattransition.org/publication/debating-the-sharing-economy.

Shirky, C. (2008). Here comes everybody: The power of organizing without organizations. South Carolina, North Charleston: Create Space Independent Publishing Platform.

Singleton Jr., R. A. \& Straits, B. C. (2010). Approaches to social research. Oxford: Oxford University, Press, Inc.

Tashakkori, A. \& Teddlie, C. (2010). SAGE Manual de métodos mistos em pesquisas de comportamento social. Thousand Oaks: Sage Publications.

Teixeira, L. B. (2016). Airbnb surfa na crise para crescer no Brasil. Revista FORBES Brasil. Recuperado em 17 dezembro, 2016 de: http://www.forbes.com.br/negocios/2016/03/ airbnb-surfa-na-crise-para-crescer-no-brasil/.

Turner, D. \& Muñoz, J. (2001). Para os filhos dos nossos filhos: uma visão da sociedade internet. São Paulo, SP: Summus Editorial.

Zervas, G., Proserpio, D. \& Byers, J. (2015). The rise of the sharing economy: Estimating the impact of Airbnb on the hotel industry. Boston University School of Management Research. Retrieved Novembro 17, 2016 from: http://ssrn.com/abstract=2366898.

\section{CONTRIBUIÇÃO DOS AUTORES NA CONSTRUÇÃO DO ARTIGO}

FERREIRA: Concepção do artigo, coleta de dados, análise de dados e desenvolvimento do texto cientifico.

SANTOS: Concepção do artigo, análise de dados e desenvolvimento do texto científico.

MÉXAS: Concepção do artigo, análise de dados e desenvolvimento do texto científico.

MEIRIÑO: Desenvolvimento do texto científico. 